\title{
FEDERICO GARCÍA LORCA: \\ AMOR DE DON PERLIMPLÍN CON BELISA EN SU JARDÍN - LA AUTOPUESTA EN ESCENA DEL AMOR Y DE LA MUERTE
}

\author{
¡Béseme con besos de su boca! \\ Cantar de los Cantares 1,2
}

Amor de don Perlimplín con Belisa en su jardín no se incluye entre las obras mayores de Federico García Lorca, tópico de la crítica convencional lorquiana que no deja de repetirse en los manuales de historia de la literatura española. Pero las últimas investigaciones dedicadas a esta obra han intentado romper con esta tradición al estimarla como una "pequeña obra maestra" y al considerarla además "una pieza clave en el teatro de Lorca", en palabras de Margarita Ucelay, editora de la obra en la editorial Cátedra.

Aquí no queremos entrar en la discusión sobre el lugar que corresponde al Amor de don Perlimplín en la producción de Lorca, ni nos interesa la historia de su recepción en la critica universitaria. Tampoco está en el centro de nuestro interés el problema del género literario. Recordemos solamente que el mismo autor subtituló su pieza Aleluya erótica en cuatro cuadros y la asoció por su musicalidad a una suerte de "operita de cámara"; la crítica por lo común suele hablar de 'farsa' o de 'farsa tragi-cómica'. ${ }^{3}$ Renunciamos igualmente a una lectura de tipo ideológico o psicológico aunque la configuración de los personajes y el desarrollo de la acción puedan invitar a efectuar un análisis de este tipo. Recordemos en este contexto que la historia triangular puesta en marcha por la configuración de los personajes -un "viejo verde, monigote sin fuerzas" (p. 287) ${ }^{4}$ y una joven con un "cuerpo grandioso" (p. 286) - constituye un obvio esquema literario clásico que no tiene nada que ver con problemas de tipo ideológico. El esquema mencionado remite, como es bien sabido, a novelas en la tradición de Boccaccio y a un sinfín de comedias y zarzuelas, esquema por el que optó Lorca como punto de partida para su pieza.

Sin querer desestimar las lecturas mencionadas preferimos centrarnos en la estructura inherente al texto. Lo que queremos señalar aquí es la tematización de la ficcionalidad de la pieza, tematización que se realiza por medio de tópicos y procedimientos técnicos propios de la literatura. En otras palabras: lo que queremos esbozar es una lectura intertextual y metaficcional de la pieza. En este contexto partimos de una definicón de la metaficcionalidad, propuesta por Ana M. Dotras. Dotras se refiere a la novela metaficcional, pero nos

\footnotetext{
Ucelay en Garcia Lorca (1986a: 183).

2 García Lorca (1986b:908). Se trata de una entrevista del 5 de abril de 1933.

3 Véase Ucelay en Garcia Lorca (1986a: 11-26).

4 Las páginas citadas se refieren a la edición de Margarita Ucelay (1986a).
} 
parece que los rasgos propios de la novela de metaficción se encuentran también en el teatro metaficcional:

La novela de metaficción es aquélla que se vuelve hacia si misma y, a través de diversos recursos y estrategias, llama la atención sobre su condición de obra de ficción y pone al descubierto las estrategias de la literatura en el proceso de creación. En esa autodenuncia de su propia ficcionalidad, al destruir el efecto de ilusión de realidad, se plantean cuestiones en torno a la naturaleza del arte y las relaciones entre el arte y la vida, la ficción y la realidad. ${ }^{5}$

Analicemos las primeras escenas del Amor de don Perlimplín y algunas secuencias clave y además las canciones repartidas en la pieza, para que se evidencie la estructura amimética y la función generadora propia de esas escenas, secuencias y canciones. Los dos puntos mencionados, es decir la estructura amimética y la técnica de la mise en abîme en forma de las canciones integradas en la pieza son dos características típicas de la literatura metaficcional, señaladas entre otros por Linda Hutcheon en su estudio Narcissistic Narrative. The Metafictional Paradox. Según Hutcheon, los textos llamados 'narcicistas' y 'metaficcionales' son

self-referring or autorepresentational: it [Narcissistic Narrative] provides, within itself, a commentary on its own status as fiction and as language, and also on its own processes of production and reception. ${ }^{6}$

En el primer cuadro se presentan las conversaciones preparatorias de la boda entre Perlimplín y Belisa. Al proponerle la criada a don Perlimplín que se case, él rechaza la propuesta: "Cuando yo era niño una mujer estranguló a su esposo. [...] Yo con mis libros tengo bastante" (p. 254). A primera vista, esta réplica parece ser nada más que cómica y remitir al personaje del solterón tradicional de la comedia que prefiere vivir encerrado en su casa por su miedo a la mujer y al matrimonio. Pero las secuencias citadas tienen un significado que nos conduce más allá de la situación dramática en la que aparecen. Tienen un valor metaficcional y señalan -en forma de mise en abime- el desarrollo de la acción y su desenlace, acción y desenlace determinados por el exceso de lecturas del protagonista. Vista así, a la réplica de don Perlimplín "Yo con mis libros tengo bastante" le corresponde una función clave en una lectura metaficcional de la pieza. Gracias a sus lecturas el protagonista es consciente de la situación en la que se encuentra y de las consecuencias que le esperan al aceptar la propuesta de la criada. En vez del matrimonio feliz que le sugieren la criada y la madre de Belisa, él va a convertirse en el viejo cornudo de la comedia que acaba como personaje ridículo o en el personaje trágico que pierde la vida por violencia ajena. Los esquemas literarios relacioniados con la configuración 'hombre viejo, mujer joven' y los procedimientos propios de la historia triangular le conducirán necesariamente a este fin. Consciente de estos dos posibles desenlaces que le están esperando, opta por la solución no ridícula. Recordemos el final de la pieza: el mismo Perlimplín acaba con su vida de marido y de amante.

\footnotetext{
Dotras (1994:27s.).

6 Hutcheon (1984:xii).
} 
Con el Amor de don Perlimplín, García Lorca no ha escrito la comedia del amor y la muerte de un viejo, víctima de una mujer y sus pasiones. Al contrario, ha escrito una obra de teatro -y ésta es nuestra hipótesis- en la que el protagonista pone en escena su propia historia, siguiendo esquemas literarios preexistentes y autodeterminándose en sus acciones por procedimientos propios de la literatura. Lo que en la novela metaficcional se manifiesta por excelencia en el yo narrador, autoconsciente de su papel creador, aparece igualmente y conforme al género dramático en el Amor de don Perlimplin: la autoconsciencia del protagonista condiciona la continua reflexión sobre el proceso de creación de la propia obra literaria. Dicho de otra manera: don Perlimplín no es víctima de una mujer ninfómana, ni de sus propias pasiones. Al contrario, es a la vez autor, director de la puesta en escena y actor principal de su propia obra, interpretando a la vez los papeles del marido y del cornudo, del amante apasionado y de la víctima del amor y además, y así termina su carrera, el papel del mártir del amor, santo que muere por el amor. Cuando muere -es el momento de la apoteosis del protagonista- "suenan campanas" (p. 289), igual que lo exigen las leyendas en el acto de la canonización de un santo. Como autor y director de escena crea un mundo de imaginación -"el triunfo de mi imaginación" (p. 285) dice textualmente-, un mundo en el que crea y dirige sus propios deseos y a la vez las fantasias eróticas de Belisa, inventando para ella el oscuro objeto del deseo e introduciéndola en los ritos y códigos del amor-pasión que, según los esquemas del triángulo erótico, es incompatible con el matrimonio. ${ }^{7}$ El personaje de Belisa, una vez introducida en el mundo de las pasiones, consecuentemente va negándose a salir de ese mundo y sigue necesariamente fijándose en el amante imaginario: “¿dónde está el joven de la capa roja?... Dios mío. ¿Dónde está?” (p. 289) - actitud que corresponde sin remedio a su construcción de mujer apasionada.

La pieza termina con un final abierto. Los papeles del marido, del amante y del director de escena se superponen y se mezclan de tal manera que no se define cuál de los papeles respectivos es el predominante. En el nivel literal, el triunfo de la imaginación -motivo recurrente de la pieza- es el triunfo del marido convertido en amante por el poder de su propia fantasía. En el nivel metaficcional es el triunfo del director de escena y de su imaginación que llega a hacerse independiente de los esquemas literarios tradicionales. Éstos hubieran exigido el triunfo del amante junto a la ridiculización del marido cornudo o la muerte del uno o la del otro y no, como en la obra de Lorca, la canonización del amante-marido y su muerte.

Centrémonos un momento en el personaje de Belisa. ¿Cómo es Belisa o, mejor dicho, cómo debe ser Belisa para que cumpla las expectativas del protagonista-director? En la imaginería generada por la lectura, lo que se denomina eterno femenino suele encarnarse en dos tipos básicos de mujer: la mujer santa, la donna angelicata, prefigurada en la Virgen, y la mujer seductora diabólica, "instrumento del espíritu del mal" - dicho con palabras de don Juan Valera-, seductora prefigurada en la diosa Venus. Resulta obvio que el protagonista-

7 A propósito de los códigos del amor véase el estudio fundamental de Niklas Luhmann (1982).

8 Valera (1992:200). 
director en su autopuesta en escena ha optado por el segundo tipo de mujer: la diosa del amor. "Amor, amor" (p. 255) canta Belisa ya antes de aparecer en el escenario y sigue cantando:

\author{
Entre mis muslos cerrados \\ nada como un pez el sol. \\ Agua tibia entre los juncos, amor. \\ ¡Gallo, que se va la noche! \\ ¡Que no se vaya, no!“ (p. 255)
}

Belisa-Venus es un obvio constructo amimético procedente de la imaginación literaria, construida no sólo con el atributo básico de Venus, el amor, sino a la vez con mitemas pertenecientes de manera general al mito de Venus. Aparece el motivo del agua -"Agua tibia entre los juncos, amor (p. 255)-, símbolo erótico por excelencia y relacionado a la vez con el mitema del nacimiento de Afrodita Anadyomene y con el de las sirenas homéricas. Totalmente conforme a esta superposición de mitos y mitemas, Belisa-Venus es la sirena-seductora que con su canto va a llevar a la muerte al que la escucha. El protagonista don Perlimplín, al oír el canto, comienza a perderse irremediablemente, es decir decide deliberadamente perderse. En el nivel de la estética de la producción o, mejor dicho, en el proceso de la puesta en escena, la presentación de una Belisa "resplandeciente de hermosura" y "medio desnuda" (p. 255) equivale a la introducción de una musa a la que, a lo largo de la acción, don Perlimplín se somete conscientemente.

La deliberada puesta en escena, como acabamos de mencionar, abarca también los lugares y el decorado del escenario. El jardin, "jardín de cipreses y naranjos" (p. 280), donde se desarrolla el último cuadro, no es el huerto andaluz y granadino, interpretación predilecta de la crítica positivista. Siempre según los esquemas literarios no cabe duda de que este jardin es el Jardín de las delicias de El Bosco y a la vez el jardin del Cantar de los Cantares, donde la esposa está esperando al esposo: "Tu plantel es un vergel de granados,/de frutales los más exquisitos,/de cipreses y de nardos" (Cantar de los Cantares 4,13). El discurso amoroso utilizado en esta escena invita a entender el texto como réplica y transformación del tradicional discurso erótico-místico. Basta citar unos versos de Belisa para que se evidencie esta observación:

\author{
Belisa lava su cuerpo \\ con agua salobre y nardos. \\ [...] \\ La noche de anis y plata \\ relumbra por los tejados. (p. 283)
}

Perlimplín, víctima de su exceso de lecturas, construye al personaje de Belisa, remitiéndose obviamente no sólo al cliché de la Venus seductora, sino también al de la esposa del Cantar de los Cantares. Al superponerse ambas cualidades prestadas a la mujer de su imaginación, la esposa se convierte en la Venus seductora y consecuentemente el jardín del Cantar de los Cantares en el Jardín de las delicias. El motivo del jardín de las delicias no hay que entenderlo sólo como lugar donde Belisa está esperando al amante, el jardín de las delicias es igualmente y en primer lugar una construcción intermedial, es decir un jardín construido 
sobre referencias latentes y al mismo tiempo obvias al Jardin de las delicias de El Bosco. No es pura casualidad que aparezcan en las canciones de Belisa los motivos del agua y del pez: ambos constituyen referencias no marcadas al famoso cuadro de El Bosco, donde tanto el agua como el pez pertenecen al arsenal de las delicias, a los amorosos deleites. Recordemos algunos pasajes ya mencionados de las canciones de Belisa: "Entre mis muslos cerrados/ nada como un pez el sol./Agua tibia entre los juncos,/amor" (p. 255) y "Belisa lava su cuerpo/con agua salobre y nardos" (p. 283).

En el nivel metaficcional del texto a las tres canciones les corresponde la función de mise en abîme. Entendemos el término de la mise en abîme en el sentido de Lucien Dällenbach que la define brevemente como "toute enclave entretenant une relation de similitude avec l'oeuvre qui la contient" interne réfléchissant l'ensemble du récit par réduplication simple, répétée ou spécieuse" ${ }^{10}$. En el contexto metaficcional, el procedimiento de la mise en abime tiene una función adicional: organiza y estructura el texto y llama la atención sobre su concepción amimética y artificial, la "un-lifelike nature of the plot"ll en palabras de Linda Hutcheon.

En otras palabras: las canciones del Amor de don Perlimplín anticipan de forma concentrada el enlace y el desenlace de la acción dramática y al mismo tiempo la presentación de los personajes, rasgo de la obra que naturalmente ha llamado la atención de la crítica. Margarita Ucelay escribe en este contexto: "Esos tres poemas equidistantes sostienen como construcción arquitectónica el peso de la obra". ${ }^{12}$ La primera canción, citada más arriba, constituye la autopresentación de Belisa. La segunda canción, epílogo del segundo cuadro y canto de Perlimplin, trata de la unión intrínseca del amor y de la muerte, y la última canción, otra vez una canción de Belisa, es el canto de la noche del amor y de la muerte. Centrémonos en la canción de Perlimplín y citemos algunos versos clave:

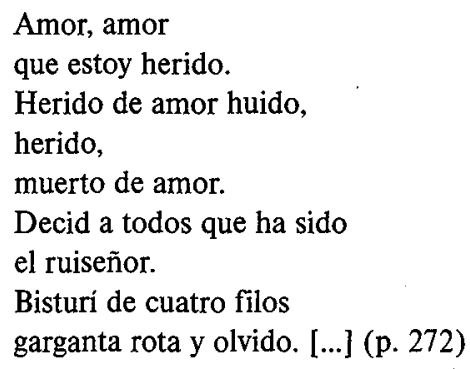

Resulta obvio que los versos citados anticipan la acción de los actos siguientes: un don Perlimplín, víctima de amor, en búsqueda de la muerte provocada por el amor. No resulta menos obvio que estos versos están construidos sobre referencias a tópicos del discurso amoroso tradicional. Aparecen las isotopías de las armas: "estoy herido", "bisturi de cuatro filos"

Dällenbach (1977:18).

10 ibid., 52.

11 Hutcheon (1984:54).

12 Ucelay en García Lorca (1986a:212). 
y aparece a la vez el motivo del ruiseñor, símbolo tradicional del amor y de la muerte. Inútil recordar aquí el famoso diálogo entre Romeo y Julieta, donde aparece textualmente el motivo en su doble función. Inútil recordar también que las isotopías de las armas constituyen a la vez los motivos básicos del discurso erótico-mundano y del discurso místico-religioso. Escribe Ovidio en los Amores (I, 9,1): "Militat omnis amans, et habet sua castra cupido" y San Juan de la Cruz en el Cántico espiritual: "Como el ciervo huyste/aviéndome herido,/salí tras tí clamando y eras ydo" 13 . No falta tampoco la referencia latente al tema de la unión intrínseca de Eros y Thanatos, referencia a la ilustre idea tan divulgada en las épocas romántica y decadentista, tan propagada por la música de Richard Wagner.

Todos los materiales que constituyen las primeras dos canciones son retomados en la última canción de Belisa. Aquí llegan a la vez a su climax sin perder su función de anticipar la acción: el agua, la noche, el amor, la muerte, las armas:

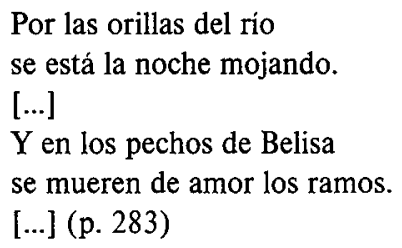

Los ramos de la canción van convirtiéndose en el „ramo ardiente de piedras preciosas“ (p. 287) que va a llevar la muerte a don Perlimplín. En esta secuencia se revela una vez más la reduplicación interior del texto, es decir la mise en abîme en la que la canción anticipa la acción dramática, concretamente el desenlace de la obra.

Amor de don Perlimplín con Belisa en su jardín no es, como podría parecer a primera vista, una simple farsa, una de las tantas farsas en torno al tema del marido cornudo, es en primer lugar una obra metaficcional. El texto lorquiano tematiza su propio proceso de creación, proceso que sigue esquemas literarios, subvertiéndolos en el caso concreto del motivo del cornudo. Visto desde la perspectiva metaficcional el protagonista de la obra, don Perlimplín, es más que el personaje principal que da el título al texto. Es a la vez el que pone en escena el juego, el que dirige a los demás figuras y el jugador del rol, capaz de presentarse en distintos papeles. En su función de marido y de amante domina los discursos amorosos respectivos y provoca y dirige a la vez el discurso amoroso del personaje femenino Belisa.

En el contexto de este proceso de creación a las tres canciones en la obra les corresponde una función particular: concentran y anticipan en forma de mise en abîme la acción y al mismo tiempo señalan de modo muy concentrado la organización del texto. A don Perlimplín como director del desarrollo textual y como dominador de los posibles fragmentos del discurso amoroso o, mejor dicho, como personaje metaficcional por excelencia, le pertenece el triunfo final que no puede ser expresado en la obra sino por él mismo. Con sus palabras nos parece adecuado terminar:

13 San Juan de la Cruz (1984:249). 
Ese es mi triunfo.

¿Qué triunfo?

El triunfo de la imaginación. (p. 285)

\section{Referencias bibliográficas}

DÄLLENBACH 1977 - Dällenbach,L.: Le récit spéculaire. Essai sur la mise en abime. Paris: Seuil.

Dotras 1994 - Dotras, A. M.: La novela española de metaficción. Madrid: Júcar.

GarCfa LorCa 1986a - Garcia Lorca, F.: Amor de don Perlimplin con Belisa en su jardin. Edición de Margarita Ucelay. Madrid: Cátedra.

GARCía LoRCa 1986b - García Lorca, F.: Obras completas. Madrid: Aguilar.

HUTCHEON 1984 - Hutcheon, L.: Narcissistic Narrative. The Metafictional Paradox. New York: Methuen.

LuHManN 1982 - Luhmann, N.: Liebe als Passion. Zur Codierung von Intimität (El amor como pasión. A propósito de la codificación de la intimidad). Frankfurt/Main: Suhrkamp.

SAn Juan De la Cruz 1984 - San Juan de la Cruz: Poesía. Ed. de Domingo Ynduráin. Madrid: Cátedra.

VALERA 1992 - Valera, J.: Pepita Jiménez. Ed. de Leonardo Romero. Madrid: Cátedra 
Drama Ljubezen don Perlimplina in Belise v njenem vrtu (Amor de don Perlimplín con Belisa en su jardín), objavljena v Buenos Airesu po pesnikovi smrti leta 1938, ni farsa o prevaranem možu, kot bi se lahko zdelo na prvi pogled. Gre predvsem za metafikcijsko delo. Lorcovo besedilo obravnava svoj lastni ustvarjalni postopek; tako pride $\mathrm{v}$ določenih literarnih shemah do zamenjave. Glavni junak don Perlimplin je istočasno režiser predstave, tisti, ki usmerja druge igralce, in sposoben igralec, ki se lahko vživi v različne vloge. Kot mož in ljubimec povsem obvladuje ljubezenski diskurz ženskega lika Belise. Ljubezen don Perlimplina in Belise v njenem vrtu je predvsem zmagoslavje imaginacije. 